\title{
Competitive Dynamics in Forecasting: The Interaction of Skill and Uncertainty ${ }^{\dagger}$
}

\author{
THEODOROS EVGENIOU ${ }^{1}$, LILY FANG ${ }^{2}$, ROBIN M. HOGARTH ${ }^{3}$ and NATALIA KARELAIA ${ }^{1 *}$ \\ ${ }^{1}$ INSEAD, Fontainebleau, France \\ ${ }^{2}$ INSEAD, Singapore \\ ${ }^{3}$ ICREA and Universitat Pompeu Fabra, Barcelona, Spain
}

\begin{abstract}
The outcomes in many competitive tasks depend upon both skill and luck. Behavioral theories on risk taking in tournaments indicate that lowskilled individuals may have incentives to take more risks than high-skilled ones. We build on these theories and suggest, in addition, that when luck is more important in determining outcomes, the increase in risk taking is larger for low-skilled than high-skilled individuals. We test this hypothesis by analyzing stock analysts' forecasts of companies' earnings per share under market conditions that vary in volatility and thus imply different levels of luck in outcomes. Specifically, noting that forecasts that deviate widely from the consensus-which is observable by the analyst - potentially carry career-related rewards but also reputational risks, we examine the degree of deviation from consensus exhibited by analysts of different skill levels (measured by both past forecasting accuracy and education) in different market conditions. We find that average deviations from consensus increase as markets become more volatile. At the same time, under conditions of high volatility, low-skilled analysts exhibit larger increases in deviations from consensus than high-skilled analysts. These field data results support our hypothesis based on of risk taking in tournaments. We discuss alternative interpretations such as, for example, self-serving attributions and indicate directions for future research. Copyright (C) 2012 John Wiley \& Sons, Ltd.
\end{abstract}

KEY WORDS risk taking; skill; chance; uncertainty; contests; financial analysts; earnings forecasts

Outcomes of many decisions depend on both skill and luck, and illuminating their relative contributions has long attracted attention in the psychological literature (e.g., Atkinson, 1957; Cohen \& Dearnaley, 1962; Langer, 1975). Heath and Tversky (1991), for example, have investigated whether greater levels of uncertainty increase risk taking. Our goal in this paper is to contrast agents' attitudes toward risk under conditions that vary in uncertainty and how changes in such attitudes differ depending on the agents' skill level. In other words, do low-skilled agents become more or less willing to take risks relative to high-skilled agents when uncertainty increases?

To do this, we study the behavior of stock analysts making forecasts of companies' earnings per share (EPS). We capture uncertainty (and hence the level of luck in outcomes) by the volatility of the companies' stock returns, and we measure analyst skill using two proxies. Our primary proxy is the analysts' track record: the accuracy of their past forecasts. As a second proxy, we use the analysts' education, specifically, whether they attended top universities. The behavioral risk taking we focus on is the extent to which the analysts' forecasts deviate from the consensus-which the analysts can observe. As we explain in the succeeding text, these deviations carry potentially important reputational risks as well as rewards for analysts and, as such, provide insight into their attitudes toward risk.

*Correspondence to: Natalia Karelaia, INSEAD, Boulevard de Constance, 77305 Fontainebleau, France. E-mail: natalia.karelaia@insead.edu †The authors' names are listed alphabetically.

\section{FOLLOWING THE CROWD OR STANDING OUT?}

Stock analysts play a key role in collecting, analyzing, and disseminating company information to investors, and making EPS forecasts is an integral part of this process. Much work in finance and accounting shows that analysts' forecasts provide market-relevant information that can move stock prices (e.g., Clement \& Tse, 2003; Gleason \& Lee, 2003). The analyst profession is characterized by high monetary stakes and asymmetric payoffs, two features that make this setting resemble a tournament and relevant for studying attitudes toward risk taking. Winners-those relatively few analysts who make accurate forecasts and good stock calls-become stars and garner multimillion dollar pay packages on Wall Street. The rest try to keep their jobs in a highly competitive labor market. Thus, analysts have strong incentives to establish reputations for being "smart", and making accurate forecasts is important for this (Fang \& Yasuda, 2009, 2011; Hong, Kubik, \& Solomon, 2000).

On the other hand, because investors value unique viewpoints, analyst "boldness"- saying something different from the crowd-is rewarded, provided, of course, that it is accurate (Hong et al., 2000). For example, when in 2007 Meredith Whitney bucked the trend and downgraded banking stocks to "sell" (in hindsight the right call), she won star status and a loyal following among investors. In this context, the "boldness" of an analyst's forecast can be measured, as in the literature, by its deviation from the consensus, which the analyst can observe because forecasts are published and not made simultaneously. In the finance and economics literature, deviation from the crowd is often referred to as antiherding or exaggeration. In contrast, herding refers to the tendency for agents to mimic their peers (Avery \& Chevalier, 
1999; Clement \& Tse, 2005; Hong et al., 2000; Scharfstein \& Stein, 1990; Trueman, 1994; see also Avci, Loufti, Mihm, \& Keck, 2011).

In the context of EPS forecasts, analysts differ in skill, a term we use broadly to include ability and knowledge. For example, some analysts may have more relevant experience than others (Clement, 1999; Mikhail, Walther, \& Willis, 1997), are more resourceful (Clement, 1999; Fang \& Yasuda, 2009), or even more closely connected with company insiders (Cohen, Malloy, \& Frazzini, 2010). In short, they are better at obtaining and/or processing information that helps them uncover the "true value" of the firms they analyze. Empirically, an extensive body of work uses analysts' track records, that is, their past forecasting accuracy as a measure of skill (e.g., Clement \& Tse, 2005; Cooper, Day, \& Lewis, 2001; Fang \& Yasuda, 2009; Hong et al., 2000).

When analysts differ in skill, reputational concern predicts that low-skilled analysts will have an incentive to herd for two reasons. First, almost by definition, low-skilled analysts do not have insights that are superior to the rest; thus, the consensus may simply be more accurate than the analyst's own forecast (Scharfstein \& Stein, 1990; Trueman, 1994). Second, as John Maynard Keynes wrote in the General Theory, "Worldly wisdom teaches that it is better for reputation to fail conventionally than to succeed unconventionally" (Keynes, 1965, p. 158). Similarly, literature in decision making suggests that relying on "the wisdom of crowds" (Surowiecki, 2004) by following the consensus is probably the most advisable strategy for decision makers who lack information about the event to be forecast (Armstrong, 2001; Clemen, 1989; Hogarth \& Karelaia, 2007; Karelaia, 2006; Larrick, Mannes, \& Soll, 2011).

On the other hand, a bold call may not be so risky for high-skilled analysts whose views might be justified by access to specific information or a unique insight. In addition, Heath and Tversky $(1991$, p. 8) argue that "competence or expertise ... helps people take credit when they succeed and sometimes provides protection against blame when they fail." That is, experts can, on occasion, attribute failure to chance whereas attributing success to knowledge.

In sum, making bold forecasts is a risky move, particularly for low-skilled analysts. Thus, reputational concerns imply that low-skilled analysts would be more prudent than their more knowledgeable peers by making forecasts that deviate less from the consensus. Theories on competition in tournaments, however, make a different prediction.

\section{RISK TAKING IN CONTESTS}

As discussed previously, the analyst profession is a competitive labor market with high monetary stakes and asymmetric payoffs. A small set of successful analysts (either by skill or by luck) make millions of dollars per year, whereas the rest try to hang on to their jobs. For example, a key indicator of success for an analyst is to be named an all-star analyst by institutional investors such as mutual funds and hedge funds through opinion polls. The influential Institutional Investor magazine conducts one such poll and awards the so-called
"All-American" title to the winners. Fewer than $8 \%$ of all analysts ever attain the All-American title, and fewer than $2 \%$ ever get named as the top analyst in his or her industry (Fang \& Yasuda, 2009, 2011). The average All-American makes $\$ 1.5 \mathrm{~m}$ a year, three times the compensation of the average senior analyst (with over 5 years of experience). Some top analysts are reported to make $\$ 15-20 \mathrm{~m}$ per year.

Thus, this set-up is similar to the tournament or contest paradigm where agents' rewards depend on their performance relative to competitors. Various scholars have suggested that in such contests, players can enhance their chances of success by increasing the variability of their responses. March (1991, p. 83) states that, "In competition to achieve relatively high positions, variability plays a positive effect." Gaba, Tsetlin, and Winkler (2004) show theoretically that a riskier performance distribution is preferred in contests with a low as opposed to high proportion of winners. As Gaba et al. (2004) suggest, increasing variability is possible in many types of contests. For example, an academic seeking tenure can choose to work on a potentially high-impact but harder — and thus riskier-problem. Financial analysts can adopt riskier forecasting strategies by deviating further from consensus.

How does skill affect risk taking in contests? Tsetlin, Gaba, and Winkler (2004) compare "weak" and "strong" agents_-as defined by past performance-in various multiround contests. They show that to maximize the probability of a positive outcome, weak agents should maximize the variability of their performance distribution (i.e., take more risks), whereas strong agents should minimize it (i.e., pursue a low-risk strategy). In a similar vein, Cabral (2003) models R\&D races where firms compete to develop new products and shows that contestants with poor past performance should prefer high-risk strategies, whereas their better performing peers should be more prudent.

These results suggest that, in a competitive environment, low-skilled analysts might have an incentive to take more risks - that is, to make forecasts that deviate more from the consensus - than their high-skilled peers. Such a high-variance strategy will at least give them a bigger chance of standing out from the crowd, which is associated with large rewards (if they are lucky and ex post "correct"). Indeed, some empirical evidence corroborates this idea. Mutual fund managers who lag behind their competitors in a given period have been observed to increase the riskiness of their portfolios in the next period in attempts to outperform competitors (Chevalier \& Ellison, 1997). Similarly, Denrell and Fang (2010) use data from the Wall Street Journal survey of economic forecasts to illustrate that poor forecasters make more extreme predictions and, as a result, ex post are overrepresented among those who are able to see "the next big thing".

\section{INTERACTION BETWEEN SKILL AND UNCERTAINTY}

The aforementioned discussions indicate that low-skilled analysts may deviate more or less from consensus than their high-skilled peers. On the one hand, research on reputational 
concerns (e.g., Scharfstein \& Stein, 1990; Trueman, 1994) predicts that they deviate less. On the other hand, theories on contests (e.g., Tsetlin et al., 2004) generate the opposite prediction.

Our contribution is to suggest that the willingness of analysts to deviate from consensus may change as the level of uncertainty they face increases, and moreover, that this change is more pronounced for low-skilled analysts. We argue that when markets are calm, deviations from consensus by low-skilled analysts are highly salient, and if these forecasts are inaccurate-which is likely-deviations will be costly because they are easily characterized as foolish. In these conditions, there is little incentive to issue extreme forecasts that deviate a lot from consensus. On the other hand, in volatile markets, extreme predictions are far less salient per se and thus, for low-skilled analysts, easier to defend-to themselves or others.

For high-skilled analysts, we would also expect increasing deviations from consensus as market volatility increases. However, because their judgments involve more skill than their low-skilled colleagues, we would not expect disproportionately large increases in deviations from consensus when uncertainty rises. The following hypothesis summarizes our reasoning.

Hypothesis: Compared with highly skilled analysts, low-skilled analysts exhibit a greater increase in their deviation from consensus in high-uncertainty periods relative to low-uncertainty periods.

As we point out in the Discussion section, this hypothesized effect is consistent with various alternative explanations. It is important to note, however, that deviations from consensus also capture the variability in analysts' forecasts. How might variability differ among low-skilled and highskilled analysts in periods of low and high market volatility? Research in psychology (in both field and laboratory settings) suggests that the variability in human predictive judgments matches the variability experienced in the environment (Brehmer, 1976). This matching hypothesis suggests two effects. First, we would expect greater variability in predictions in periods of high as opposed to low volatility for both skill types. Second, because low-skilled analysts generally know less than high-skilled analysts, we expect that, as a group, the forecasts of the former will exhibit more variability than those of the latter. That is, there should be more variability in the forecasts of low-skilled analysts compared with high-skilled analysts, in conditions of both low and high market volatility. What the matching hypothesis does not predict is that in high-volatility conditions, we will observe additional variability by low-skilled analysts.

The existing literature has not considered how analysts' degree of deviation from consensus changes when the volatility of financial markets-and thus uncertainty-increases. The domain of financial analysts provides a unique opportunity to use field data to investigate the interactive effect of uncertainty and analysts' skill on their deviation from consensus. We use an extensive dataset to test our hypothesis that heightened uncertainty in the environment triggers a greater behavioral change-as measured by deviation from consensus - in low-skilled analysts as compared to their high-skilled peers. Our dataset includes all quarterly EPS forecasts made by 4732 stock analysts from 1990 to 2009 for all US stocks covered by these analysts. Using two measures of analyst skill- the track record of past forecast accuracy (over the past 3 years) and education-our main prediction is validated, namely, low-skilled analysts (those with poor past track records or those who did not attend prestigious universities) exhibit larger increases in deviations from consensus in volatile relative to calm markets as compared with high-skilled analysts.

Our results on the interaction between uncertainty and skill in forecasting provide a threefold contribution. First, we add to the literature on judgment and decision making under uncertainty by showing the interplay of uncertainty and skill using large-scale field data. Second, we contribute to the literature on behavior in contests since financial analysts operate in an environment characterized by fierce competition. Third, this study enriches the finance literature on the behavior of high-skilled and low-skilled analysts by demonstrating that uncertainty (as measured by market volatility) plays an important role in distinguishing the quality of forecasts issued by the two types.

\section{METHOD}

\section{Data}

We used quarterly EPS forecast data from $\mathrm{I} / \mathrm{B} / \mathrm{E} / \mathrm{S}$ for the period from 1 January 1990 to 31 December 2009. We performed data preprocessing steps common in the literature that uses this type of data (e.g., Clement \& Tse, 2005; Hilary \& Menzly, 2006; Hong et al., 2000). In particular, we only kept forecasts made during the same quarter of the company announcement. We removed forecasts reported after the company announcement. All actual and predicted quarterly EPS were divided by the average stock price of the company during the quarter and multiplied by 100 . Hence, all EPS, forecasted and actual, were "dollars earned/lost per 100 dollars". We only used company quarters if the average stock price during the quarter is more than five dollars, and we only used the last EPS forecast of each analyst in each quarter. We also controlled for the number of days left from the time of this last company forecast of the analyst in the quarter till the company announcement date. Finally, we removed outliers defined as company quarters for which at least one analyst had a forecast error larger than 40 (hence, more than 40 dollars per 100 dollars) — which was the 99th percentile of the maximum forecast error during a calendar quarter.

Definitions of the variables used in the analysis appear in Table 1. We defined "deviation-from-consensus" as the absolute difference between an analyst's EPS forecast and the mean EPS forecasts made prior to this analyst's forecast during the same quarter for the same firm. In other words, it is the distance between an analyst's forecast and the consensus that the analyst can observe at the time of making his or her own forecast.

To have reliable estimates of deviation-from-consensus, we only considered company quarters where we had at least five analysts, as also done in the literature (e.g., Hilary \& 
Table 1. Definitions of variables (in alphabetic order)

\begin{tabular}{|c|c|}
\hline$D A Y S_{t}^{i c}$ & $\begin{array}{l}\text { he number of days between the last forecast of analyst } i \text { for company } c \text { in calendar quarter } t \text {, (namely } F E P S_{t}^{i c} \text { ) and } \\
\text { e date of the company announcement, } E P S_{t}^{c} \text {, in that quarter. }\end{array}$ \\
\hline$D E V C_{t}^{i c}$ & $\begin{array}{l}\text { The absolute deviation from consensus of analyst } i \text { in calendar quarter } t \text { for company } c \text { defined as } D E V C_{t}^{i c}= \\
\mid F E P S_{t}^{i c}-\left(\text { Average until time of forecast }\left(F E P S_{t}^{c}\right)\right) \mid \text {. }\end{array}$ \\
\hline Differ & Defined as $H M E A N_{-} D E V C_{0(t-1)}^{i}-L M E A N_{-} D E V C_{0(t-1)}^{i}$ \\
\hline$E P S_{t}^{c}$ & $\begin{array}{l}\text { Actual EPS announced by company } c \text { at the end of quarter } t \text {. It is divided by the average stock price of company } c \\
\text { during quarter } t \text { and multiplied by } 100 \text {. }\end{array}$ \\
\hline$E X P_{t}^{i}$ & This is the number of calendar quarters for which analyst $i$ has been in the data until time $t$. \\
\hline$F E P S_{t}^{i c}$ & erage stock price of \\
\hline$F E R R_{t}^{i c}$ & absolute forecast error of analyst $i$ for company $c$ in calendar quarter $t$ defined as FERR $R_{t}^{i c}=\left|F E P S_{t}^{i c}-E P S_{t}^{c}\right|$. \\
\hline$L S I Z E_{t}^{c}$ & $\begin{array}{l}\mathrm{m} \text { of the market capitalization (average quart } \\
t \text {. }\end{array}$ \\
\hline$M E A N \_F E R R_{t s}^{i}$ & $\begin{array}{l}\text { The average forecast error of analyst } i \text { across all } c \\
\text { including quarters } t \text { and } s \text {. Time index } 0 \text { is for the } \\
\text { case). For example } M E A N_{-} F E R R_{(t-1)(t-1)}^{i} \text { is the av }\end{array}$ \\
\hline 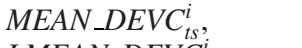 & anies followed by that \\
\hline & \\
\hline$H M E$ & low-uncertainty $(U N C)$ quarters, whereas $H M E A N_{-} D E V C_{t s}^{i}$ is \\
\hline$N_{t}^{c}$ and $S N_{t}^{i}$ & $\begin{array}{l}\text { The number of analysts forecasting for company } c \text { in calendar quarter } t \text { and the number of companies analyst } i \\
\text { follows in quarter } t \text {, respectively. }\end{array}$ \\
\hline$S K I L L_{t}^{i}$ & $\begin{array}{l}\text { Our main proxy for the skill of analyst } i \text {. It is the average forecast error of the analyst, } F E R R_{t}^{i c} \text {, over all companies } c \\
\text { and over all quarters over the past } 3 \text { years (12 quarters), that is } S K I L L_{t}^{i}=-M E A N_{-} F E R R_{(t-12)(t-1)} \text {. }\end{array}$ \\
\hline$U N C_{t}^{c}$ & $\begin{array}{l}\text { A dummy that is } 1 \text { if uncertainty is high and } 0 \text { otherwise. Uncertainty is the standard deviation of the daily stock } \\
\text { returns of company } c \text { during quarter } t \text {. } U N C_{t}^{c} \text { is } 1 \text { if the standard deviation is in the top } 20 \% \text { of the standard } \\
\text { deviations of all previous quarters of company } c \text {. }\end{array}$ \\
\hline
\end{tabular}

EPS, earnings per share.

Menzly, 2006; Hong et al., 2000). Varying this threshold did not alter the results qualitatively. We defined the forecast error of an analyst for a company in a quarter to be the absolute difference between the forecasted and actual EPS. Means, standard deviations, and correlations of the main variables appear in Table 2.

\section{Measures}

Skill

Although skill is not directly measurable, it is reflected in an analyst's track record-how accurate she or he has been in the past. Following a large body of existing literature, we used the accuracy of an analyst's past forecasts as a proxy for the analyst's skill (e.g., Clement \& Tse, 2005; Cooper,
Day, \& Lewis, 2001; Fang \& Yasuda, 2009). Specifically, we used the negative of the mean absolute forecast error (so the higher, the more skill) of the analyst over the previous 12 quarters available for this analyst, namely $S K I L L_{t}^{i}=$ $-M E A N_{-} F E R R_{(t-12)(t-1)}^{i}$. By considering a rolling 12-quarter time window of performance, we allowed for skill to change slowly over time. Using longer lengths of time, including the average error because the very first time an analyst appears in the dataset, namely $S K I L L_{2 t}^{i}=$ $-M E A N_{-} F E R R_{0(t-1)}^{i}$, led to similar results. The correlation between consecutive nonoverlapping 12-quarter windows of SKILL was .32, indicating that there was a persistent, analyst-level effect in this measure, consistent with previous literature (e.g., Clement \& Tse, 2003; Fang \& Yasuda, 2009). In the analysis in the succeeding text, we only used data from

Table 2. Descriptive statistics

\begin{tabular}{|c|c|c|c|c|c|c|c|c|c|c|c|c|c|c|c|}
\hline & \multirow[b]{2}{*}{ Variable } & \multirow[b]{2}{*}{ Mean } & \multirow[b]{2}{*}{ Median } & \multirow[t]{2}{*}{ SD } & \multicolumn{2}{|c|}{ Percentile } & \multicolumn{9}{|c|}{ Correlations } \\
\hline & & & & & 25 th & 75th & 1 & 2 & 3 & 4 & 5 & 6 & 7 & 8 & 9 \\
\hline 1 & Actual EPS, $E P S_{t}^{c}$ & .94 & 1.00 & 5.28 & .42 & 1.65 & & & & & & & & & \\
\hline 2 & Forecasted EPS, FEPS ${ }_{t}^{i c}$ & 1.05 & 1.03 & 4.21 & .47 & 1.63 & $.94 *$ & & & & & & & & \\
\hline 3 & Forecast error, FERR $R_{t}^{i c}$ & .40 & .10 & 1.51 & .03 & .28 & $-.20 *$ & $-.02 *$ & & & & & & & \\
\hline 4 & Deviation-from-consensus, $D E V C_{t}^{i c}$ & .21 & .05 & 1.00 & .02 & .15 & $.15^{*}$ & $.17 *$ & $.33^{*}$ & & & & & & \\
\hline 5 & Analysts' experience, $E X P_{t}^{i}$ & 26.90 & 23.00 & 13.14 & 17.00 & 34.00 & $.02 *$ & $.02 *$ & $.01 *$ & $.01 *$ & & & & & \\
\hline 6 & Analysts' skill, SKILL $L_{t}^{i}$ & 31.93 & 32.05 & .44 & 31.89 & 32.14 & $.05^{*}$ & $.03 *$ & $-.20 *$ & $-.14 *$ & $.04 *$ & & & & \\
\hline 7 & Number of analysts per stock, $N_{t}^{c}$ & 11.30 & 9.00 & 7.13 & 6.00 & 14.00 & $-.01 *$ & $-.01 *$ & $-.01 *$ & $.02 *$ & $.04 *$ & $.01 *$ & & & \\
\hline 8 & Number of stocks per analyst, $S N_{t}^{i}$ & 11.06 & 10.00 & 7.47 & 6.00 & 14.00 & $.02 *$ & $.02 *$ & $.03 *$ & $.03 *$ & $.07 *$ & $-.07 *$ & $.08^{*}$ & & \\
\hline 9 & Days before EPS announcement, $D A Y S_{t}^{i c}$ & 43.66 & 50.00 & 23.36 & 21.00 & 64.00 & $.00 *$ & $.00 *$ & $-.00 *$ & $-.07 *$ & $.04 *$ & $.01 *$ & $-.12 *$ & $.17 *$ & \\
\hline 10 & $\log$ of market capitalization, $L S I Z E_{t}^{c}$ & 14.57 & 14.45 & 1.49 & 13.51 & 15.51 & $.07 *$ & $.06^{*}$ & $-.13 *$ & $-.10^{*}$ & $.08 *$ & $.09 *$ & $.46^{*}$ & $.00^{*}$ & $.03 *$ \\
\hline
\end{tabular}

SD, standard deviation; EPS, earnings per share. The data include 429515 unique analyst-company-quarter observations, 79827 unique company-quarter observations, 75717 unique analyst-quarter observations, and 4732 unique analysts. $* p<.01$. 
analysts for whom we had at least 12 quarters of data (so that SKILL can be estimated) and at least one quarter of data for each particular company (so that past short-term company specific performance and deviation-from-consensus could be used as control variables).

\section{Uncertainty}

We measured the degree of uncertainty about a firm during a quarter as the standard deviation of the daily stock returns of that company during the quarter. This is a firm-level measure that changes every quarter, as opposed to a market-level measure such as overall market volatility. We used this measure because analysts make forecasts for firm-specific EPS, and the relevant forecasting environment should capture the uncertainty in that firm's prospects. This firm-specific measure more accurately reflects the level of uncertainty commonly faced by those analysts making forecasts for that firm and allows for more variation than a measure of market-level volatility. To compare analysts' behavior under low and high uncertainty, we defined as high-uncertainty company quarters those when the standard deviation of the daily returns of the company's stock was within the top $20 \%$ of the standard deviations of daily returns for that company in all previous quarters (see Table 1, variable UNC). Our results are robust to changes of this $20 \%$ threshold and also hold if we use the continuous measure of actual standard deviation instead of the dummy variable measure $U N C$.

\section{RESULTS}

\section{Interaction between uncertainty and skill}

We first note that the mean across companies and quarters of the standard deviation of the analysts' (company-quarter) forecasts (FEPS) was .16 for the low-uncertainty quarters and .34 for the high-uncertainty quarters. This implies that when uncertainty is high, the overall variability across forecasts is greater. In turn, the larger variance across forecasts in high-volatility periods indicates that analysts exhibit more divergent opinions in such times, consistent with the matching hypothesis (Brehmer, 1976).

To examine the interactive effect of uncertainty and skill on analysts' deviations-from-consensus, we used multivariate analyst-company fixed-effect regressions. In Model 1, we used skill (proxied by past accuracy) as the key explanatory variable. In Model 2, we added uncertainty (proxied by stock-level return volatility) and the interaction of skill and uncertainty. In both models, we included a number of controls that past research identified as potentially relevant to analysts' deviations-from-consensus. First, previous studies suggest that analysts with longer careers in the industry might take more risk by deviating from consensus because they face fewer reputational and career concerns than less experienced analysts (e.g., Chevalier \& Ellison, 1999; Clement \& Tse, 2005; Hong et al., 2000). We thus controlled for analysts' overall experience, EXP $t_{t}^{i c}$ (using companyspecific experience, instead, does not alter the results). Second, we included the previous period deviation-fromconsensus and forecast accuracy, DEVC $C_{t-1}^{i c}$ and $F E R R_{t-1}^{i c}$, to control for the possibility that analysts change their behavior as a reaction to their poor performance in the previous period (e.g., Clarke \& Subramanian, 2006; Hilary \& Menzly, 2006). Third, we controlled for the number of companies each analyst follows, $S N_{t}^{i}$, because analysts with large portfolios may be more likely to deviate from consensus (Clement $\&$ Tse, 2005). Fourth, consistent with previous research using similar data (e.g., Hilary \& Menzly, 2006), we controlled for the amount of information available to the market for a particular firm by including the timing of forecast, $D A Y S_{t}^{i c}$, the size of the firm, $L S I Z E_{t}^{c}$, and the number of analysts making forecasts for the firm, $N_{t}^{c}$ (see Table 1 for definitions). Finally, we included a full set of year dummies. The full model tested is

$$
\begin{aligned}
& D E V C_{t}^{i c}=\alpha+\beta_{1} S K I L L_{t}^{i}+\beta_{2} U N C_{t}^{c}+\beta_{3}\left(S K I L L_{t}^{i *} U N C_{t}^{c}\right) \\
& +\beta_{4} E X P_{t}^{i}+\beta_{5} F_{E R R_{t-1}^{i c}}+\beta_{6} D E V C_{t-1}^{i c}+\beta_{7} S N_{t}^{i}+\beta_{8} N_{t}^{c} \\
& +\beta_{9} D A Y S_{t}^{i c}+\beta_{10} L S I Z E_{t}^{c}+\beta_{11} D_{T I M E}+\alpha^{i c}+\varepsilon_{t}^{i c}
\end{aligned}
$$

where DTIME is a dummy for each year (from 1990 to 2009), $\alpha^{i c}$ is the analyst-firm fixed effect, and $\varepsilon_{t}^{i c}$ is the error term. In all models, standard errors were adjusted for clustering by analysts and firms because observations are independent across clusters but not necessarily within clusters. Estimating Fama-Macbeth regressions (Fama \& MacBeth, 1973) instead does not alter the results.

The results are displayed in Table 3. First, skill had a neg-

\begin{tabular}{|c|c|c|}
\hline & Model 1 & Model 2 \\
\hline$S K I L L_{t}^{i}$ & $\begin{array}{r}-.12^{*} \\
(-6.54)\end{array}$ & $\begin{array}{r}-.08^{*} \\
(-4.57)\end{array}$ \\
\hline$U N C_{t}^{c}$ & & $\begin{array}{r}7.11 * \\
(8.35)\end{array}$ \\
\hline $\operatorname{SKILL}_{t}^{i *} U N C_{t}^{c}$ & & $\begin{array}{r}-.22^{*} \\
(-8.26)\end{array}$ \\
\hline$E X P_{t}^{i}$ & $\begin{array}{r}.01 * \\
(7.75)\end{array}$ & $\begin{array}{r}.01 * \\
(6.89)\end{array}$ \\
\hline$F E R R_{t-1}^{i c}$ & $\begin{array}{l}.09 * \\
(8.82)\end{array}$ & $\begin{array}{r}.09 * \\
(8.71)\end{array}$ \\
\hline$D E V C_{t-1}^{i c}$ & $\begin{array}{c}-.06 \\
(-1.59)\end{array}$ & $\begin{array}{c}-.06 \\
(-1.57)\end{array}$ \\
\hline$S N_{t}^{i}$ & $\begin{array}{l}.00 * \\
(4.73)\end{array}$ & $\begin{array}{r}.00 * \\
(4.47)\end{array}$ \\
\hline$N_{t}^{c}$ & $\begin{array}{r}.01 * \\
(32.86)\end{array}$ & $\begin{array}{r}.01 * \\
(31.93)\end{array}$ \\
\hline$D A Y S_{t}^{i c}$ & $\begin{array}{r}-.00 * \\
(-23.82)\end{array}$ & $\begin{array}{r}-.00^{*} \\
(-23.61)\end{array}$ \\
\hline$L S I Z E_{t}^{c}$ & $\begin{array}{r}-.27 * \\
(-28.80)\end{array}$ & $\begin{array}{r}-.26^{*} \\
(-28.22)\end{array}$ \\
\hline Intercept & $\begin{array}{r}7.80^{*} \\
(11.98)\end{array}$ & $\begin{array}{r}6.41 * \\
(10.08)\end{array}$ \\
\hline $\begin{array}{l}N \\
R^{2}\end{array}$ & $\begin{array}{r}429515 \\
0.561\end{array}$ & $\begin{array}{r}429515 \\
0.562\end{array}$ \\
\hline
\end{tabular}
ative and statistically significant effect, suggesting that, on

Table 3. Regression analyses predicting deviation from consensus

Dependent variable is a deviation from consensus $D E V C_{t}^{i c}$. Entries are coefficients from fixed-effect (analyst-company) regressions. Robust $t$-statistics are provided in parentheses. Standard errors are deflated for autocorrelation and heteroscedasticity. Time dummies are included. ${ }^{*} p<.01$. 
average, low-skilled analysts deviate from consensus more than their highly skilled peers. This is consistent with the literature on contests (e.g., Tsetlin et al., 2004). Second, uncertainty had a positive and statistically significant effect, suggesting that in times of high uncertainty deviation-fromconsensus increases for all analysts. This result is consistent with the past research on financial analysts (Song, Kim, \& Won, 2009) and the matching hypothesis (Brehmer, 1976). Third, and most important, the interactive effect of skill and uncertainty on deviation-from-consensus was negative and statistically significant, providing support for our main hypothesis that low-skilled analysts increase their deviation-from-consensus more when uncertainty increases.

To interpret this interaction, we plotted the values of deviation-from-consensus - as predicted by our model-at high (one standard deviation above mean) and low (one standard deviation below the mean) values of analysts' skill, following the methodology suggested by Aiken and West (1991). For comparison, we also included the predicted values of deviation-from-consensus evaluated at the mean level of analysts' skill. For each level of skill, we calculated the predicted values of deviation-from-consensus ( $y$-axis) for low-uncertainty and high-uncertainty ( $x$-axis). Control variables were entered in this calculation at their mean level, except for the dummy variables for each year that were entered at the value of zero. As Figure 1 also shows, the effect of uncertainty on analysts' deviation-from-consensus was stronger for low-skilled analysts.

To further analyze the interaction, we tested analogous regression models on the two subgroups of analysts: a group with skill below the median (32.05) and a group with skill equal to or superior than the median. The analyses confirmed that the positive relationship between uncertainty and deviation from consensus was stronger for low-skilled analysts $(N=228462, b=.13, t=12.23, p<.001)$ than for their highly skilled peers $(N=201053, b=.05, t=12.13$, $p<.001)$ : the $F$-test for coefficient equality showed that the probability of the two coefficients being equal was less than .001. Thus, compared with their more skilled peers, low-skilled analysts exhibit larger increases in deviationfrom-consensus in high-uncertainty periods relative to lowuncertainty periods.

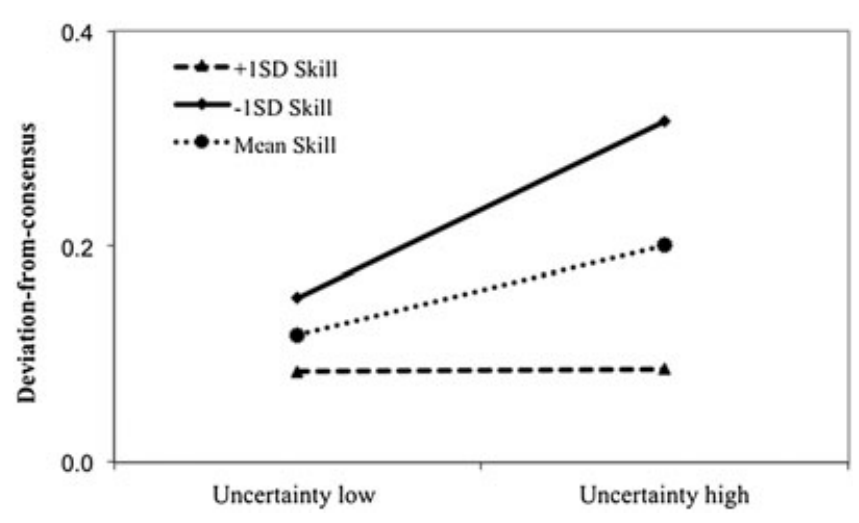

Figure 1. Simple slopes for deviation-from-consensus: Skill moderates the effect of uncertainty

\section{Further tests}

Length of career

As a robustness check, we repeated the same analysis for analysts with longer and shorter experiences. We expected the main result to hold in both populations. As suggested by previous work (e.g., Chevalier \& Ellison, 1999; Hong et al., 2000), analysts with more experience ("older" analysts) may have fewer reputational and career concerns than younger ones. Hence, we would expect that the interaction of skill and uncertainty might be more pronounced for the older analysts. These additional analyses revealed that for both younger (the analysts at the bottom quartile in terms of years of experience) and older analysts (the analysts at the top quartile in terms of years of experience), the interaction was negative and statistically significant $(N=40118, b=-.12$, $t=-2.08, p<.05$ for younger analysts and $N=29167$, $b=-.26, t=-3.36, p<.001$ for older analysts), thereby supporting our main result. The significance level of the effect for older analysts was larger than for younger ones ( $t=-3.36$ vs. $t=-2.08)$, but the difference between the interaction coefficients was not statistically significant ( $p<.12, F$-test), suggesting that factors other than reputational and career concerns might be affecting analysts' behavior.

\section{Education as a proxy for skill}

In the aforementioned analysis, we used past forecast accuracy to proxy for analysts' skill. As an additional robustness test, we repeated our analyses using a different measure. Specifically, we used educational data because empirical research suggests that scholastic aptitude is correlated with unobserved "ability". For example, mutual fund managers with higher SAT (a standardized test for college admissions in the US) scores outperform managers with lower scores (Chevalier \& Ellison, 1999). Education data-university or postgraduate degree information —were available for a subsample of 1913 analysts. Because we do not have individual SAT scores and because average SAT scores of schools change from year to year, we used as an alternative proxy of skill whether the analyst attended an Ivy League college, Massachusetts Institute of Technology (MIT), or Stanford. Aggregate statistics show that the average SAT scores of students in Ivy League colleges, MIT, and Stanford are about 200 points higher than those in other top 50 universities (see, e.g., http://www.satscores.us/). Hence, we repeated our main analysis, presented in Table 3, using this proxy of skill and following the exact same econometric specifications.

Table 4 displays the results of this analysis. The results replicate those presented in Table 3. The interaction of skill—proxied by education-and market uncertainty was negative and marginally significant at $p=.064$, suggesting that analysts who attended high-ranking schools did exhibit somewhat smaller increases in deviation-from-consensus when volatility increased. The weaker statistical significance compared to our main test (Table 3) indicates that education is a noisy proxy of skill.

\section{Using differential deviation to predict future performance}

Our results suggest that, compared with high-skilled analysts, low-skilled analysts exhibit greater increases in 
Table 4. Replicating main results using education as skill proxy

\begin{tabular}{|c|c|c|}
\hline & Model 1 & Model 2 \\
\hline Elite_School ${ }^{i}$ & $\begin{array}{c}-.01 \\
(-1.72)\end{array}$ & $\begin{array}{l}-.00 \\
(-.62)\end{array}$ \\
\hline$U N C_{t}^{c}$ & & $\begin{array}{r}.13 * \\
(12.88)\end{array}$ \\
\hline Elite_School $^{i *} U N C_{t}^{c}$ & & $\begin{array}{r}-.03^{\mathrm{a}} \\
(-1.85)\end{array}$ \\
\hline$E X P_{t}^{i}$ & $\begin{array}{r}.00 * \\
(2.66)\end{array}$ & $\begin{array}{r}.00 * \\
(2.64)\end{array}$ \\
\hline$F E R R_{t-1}^{i c}$ & $\begin{array}{l}.10 * \\
(9.92)\end{array}$ & $\begin{array}{r}.10^{*} \\
(9.86)\end{array}$ \\
\hline$D E V C_{t-1}^{i c}$ & $\begin{array}{r}.06^{*} \\
(2.81)\end{array}$ & $\begin{array}{r}.06 * \\
(2.82)\end{array}$ \\
\hline$S N_{t}^{i}$ & $\begin{array}{c}.00 \\
(1.05)\end{array}$ & $\begin{array}{l}.00 \\
(.58)\end{array}$ \\
\hline$N_{t}^{c}$ & $\begin{array}{r}.01 * \\
(24.30)\end{array}$ & $\begin{array}{r}.01 * \\
(23.46)\end{array}$ \\
\hline$D A Y S_{t}^{i c}$ & $\begin{array}{r}-.00 * \\
(-15.78)\end{array}$ & $\begin{array}{r}-.00 * \\
(-15.56)\end{array}$ \\
\hline$L S I Z E_{t}^{c}$ & $\begin{array}{r}-.17 * \\
(-26.48)\end{array}$ & $\begin{array}{r}-.16^{*} \\
(-26.03)\end{array}$ \\
\hline Intercept & $\begin{array}{r}2.42 * \\
(26.33)\end{array}$ & $\begin{array}{r}2.27 * \\
(25.16)\end{array}$ \\
\hline $\begin{array}{l}N \\
R^{2}\end{array}$ & $\begin{array}{r}166418 \\
0.353\end{array}$ & $\begin{array}{r}166418 \\
0.355\end{array}$ \\
\hline
\end{tabular}

Dependent variable is a deviation from consensus $D E V C_{t}^{i c}$. Entries are coefficients from fixed-effect (analyst-company) regressions. Robust $t$-statistics are provided in parentheses. Standard errors are deflated for autocorrelation and heteroscedasticity. Time dummies are included. $* p<.01,{ }^{a} p=.064$.

deviation-from-consensus in volatile relative to calm markets. Does this differential deviation add incremental value-after controlling for analysts' past performance (i.e., past accuracy) - in predicting their future forecasting performance? After all, one main objective for investors is to identify analysts who can provide accurate forecasts. To assess the predictive value of this differential deviation, for each analyst, we computed the difference in his or her mean deviation-from-consensus between high-uncertainty and low-uncertainty periods:

$$
\begin{aligned}
\text { Differential_Deviation }_{t}^{i}= & H M E A N \_D E V C_{0(t-1)}^{i} \\
& -L M E A N \_D E V C_{0(t-1)}^{i}
\end{aligned}
$$

This measure assesses the extent to which the analyst deviates more from consensus in volatile than in calm markets. It uses past information based solely on the behavioral effect we have demonstrated. Importantly, our objective was not to forecast future accuracy using past accuracy but to assess the incremental predictive value of differential deviation. We expected that the larger this deviation, the lower the skill of the analyst, hence the larger the future forecast error.

To examine whether differential deviation helps predict future forecasting performance, we used multivariate analystcompany fixed-effect regressions. Our dependent variable was forecast error, FERR $t_{t}^{i c}$. In Model 1, we entered skill, $S K I L L_{1 t}^{i}$ (proxied by past long-term accuracy) — to allow for analyst-level persistence and the same control variables as in Table 3. In Model 2, instead of skill, we entered the measure of differential deviation, Differential_Deviation ${ }_{t}^{i}$. Finally, in Model 3, we estimated a model with both differential deviation and skill to assess the incremental value of differential deviation for predicting forecasting accuracy. Results, presented in Table 5, confirmed that skill (proxied by past long-term accuracy) is negatively related to forecast error, suggesting that skill is persistent. Most important, the coefficient of differential deviation was statistically significant and positive even after controlling for skill, suggesting that differential deviation predicts forecasting accuracy above and beyond past performance. We also note that when both variables are included to predict future performance (Model 3), their magnitude and statistical significance do not change substantially.

\section{DISCUSSION}

We studied risk taking of stock analysts under market conditions that vary in volatility and thus imply different levels of luck in outcomes. We characterized the degree of risk that analysts take by the extent to which their forecasts deviate from the consensus. We predicted and tested the hypothesis that low-skilled analysts take greater risks in volatile markets by issuing forecasts that deviate more widely from consensus than in calm markets. Importantly, although all analysts' forecasts are more dispersed when markets are volatile, our results revealed that the differential deviationfrom-consensus between volatile and calm conditions exhibited by low-skilled analysts is larger than the corresponding differential exhibited by high-skilled analysts.

\begin{tabular}{|c|c|c|c|}
\hline & Model 1 & Model 2 & Model 3 \\
\hline$S K I L L_{t}^{i}$ & $\begin{array}{r}-.28 * \\
(-8.18)\end{array}$ & & $\begin{array}{r}-.26^{*} \\
(-7.85)\end{array}$ \\
\hline Differential_Deviation ${ }_{t}^{i}$ & & $\begin{array}{r}-.14 * \\
(-5.88)\end{array}$ & $\begin{array}{r}-.11 * \\
(-5.13)\end{array}$ \\
\hline$E X P_{t}^{i}$ & $\begin{array}{r}.03^{*} \\
(15.84)\end{array}$ & $\begin{array}{r}.03^{*} \\
(15.89)\end{array}$ & $\begin{array}{r}.03 * \\
(15.87)\end{array}$ \\
\hline$F E R R_{t-1}^{i c}$ & $\begin{array}{c}.04 * \\
(2.71)\end{array}$ & $\begin{array}{r}.04 * \\
(3.10)\end{array}$ & $\begin{array}{r}.03^{*} \\
(2.67)\end{array}$ \\
\hline$D E V C_{t-1}^{i c}$ & $\begin{array}{l}.16^{*} \\
(7.60)\end{array}$ & $\begin{array}{r}.16^{*} \\
(7.63)\end{array}$ & $\begin{array}{r}.15^{*} \\
(7.52)\end{array}$ \\
\hline$S N_{t}^{i}$ & $\begin{array}{r}.00 * \\
(2.98)\end{array}$ & $\begin{array}{r}.00 * \\
(3.06)\end{array}$ & $\begin{array}{r}.00 * \\
(3.05)\end{array}$ \\
\hline$N_{t}^{c}$ & $\begin{array}{r}.01 * \\
(17.87)\end{array}$ & $\begin{array}{r}.01 * \\
(17.98)\end{array}$ & $\begin{array}{r}.01 * \\
(17.84)\end{array}$ \\
\hline$D A Y S_{t}^{i c}$ & $\begin{array}{r}.00 * \\
(11.93)\end{array}$ & $\begin{array}{r}.00^{*} \\
(12.11)\end{array}$ & $\begin{array}{r}.00 * \\
(11.95)\end{array}$ \\
\hline$L S I Z E_{t}^{c}$ & $\begin{array}{r}-.56^{*} \\
(-40.41)\end{array}$ & $\begin{array}{r}-.57 * \\
(-40.65)\end{array}$ & $\begin{array}{r}-.56^{*} \\
(-40.44)\end{array}$ \\
\hline Intercept & $\begin{array}{l}17.00^{*} \\
(15.39)\end{array}$ & $\begin{array}{r}6.16^{*} \\
(15.68)\end{array}$ & $\begin{array}{l}14.79 * \\
(13.38)\end{array}$ \\
\hline $\begin{array}{l}N \\
R^{2}\end{array}$ & $\begin{array}{r}416883 \\
0.472\end{array}$ & $\begin{array}{r}416883 \\
0.471\end{array}$ & $\begin{array}{r}416883 \\
0.472\end{array}$ \\
\hline
\end{tabular}

Table 5. Regression analyses predicting forecast accuracy

Dependent variable is a forecast error $F E R R_{t}^{i c}$. Entries are coefficients from fixed-effect (analyst-company) regressions. Robust $t$-statistics are provided in parentheses. Standard errors are deflated for autocorrelation and heteroscedasticity. Time dummies are included. $* p<.01$. 


\section{Theoretical contribution}

Our result on the interaction between skill and uncertainty in forecasting provides an important contribution to different streams of research. First, our findings extend knowledge on human judgment and behavior under uncertainty. For example, Heath and Tversky (1991) provided experimental evidence of a so-called competence effect whereby individuals prefer ambiguous alternatives when they feel competent about the source of uncertainty. Our research, based on large-scale field data, suggested an extension of this finding. We showed that, under competitive remuneration schemes, higher uncertainty leads to low-skilled individuals exhibiting even greater risk taking than their more skilled (i.e., competent) peers. Moreover, the interaction we observed between skill and uncertainty refines our understanding of the main effects of the latter. For example, this interaction would not be predicted by the matching hypothesis (Brehmer, 1976) nor would one anticipate it by considering the "hard-easy" effect in judgments of relative self-competence (Moore \& Healy, 2008). This holds that people tend to overestimate their competence relative to others in easy situations but underestimate this in difficult tasks. In other words, people implicitly take more relative risk when tasks are easy. If anything, our results run counter to this implication. That is, whereas we did not measure self-assessed competence per se, we note that forecasting is more difficult in times of high volatility, and yet this is when low-skilled analysts exhibit more boldness in their forecaststhat could indicate more relative overconfidence.

Second, our research provides a theoretical and methodological contribution to the literature that models human judgment. Specifically, researchers have shown how accuracy across a set of judgments is affected by both the variability of the predictions made by individuals and the level of environmental uncertainty (Karelaia \& Hogarth, 2008; Lee \& Yates, 1992). In this paper, we also considered the interrelation between accuracy and the variability of judgments. However, in contrast to previous research, we showed that past long-term accuracy (i.e., our primary measure of skill) affects judgmental variability and that this effect differs as a function of skill and the variability of the prediction environment.

Third, our research also provides insights on behavior in contests. That is, the situation we studied can be characterized as a tournament where analysts compete for financial compensation and professional recognition, and "winners" and "losers" are determined by both skill and luck. Previous literature has suggested that, in such settings, risk-taking behavior differs between individuals with low and high skills (Tsetlin et al., 2004). Specifically, the former take more risk in attempts to outperform their stronger competitors (Chevalier \& Ellison, 1997). Our finding that low-skilled analysts deviate more from consensus than their highly skilled peers is consistent with this literature. Moreover, our main empirical result that low-skilled analysts exhibit greater increase in deviation-from-consensus when market volatility increases is also consistent with experimental evidence from market-entry contests where payoffs are determined by relative performance (e.g., Camerer \& Lovallo, 1999). In one such study, Karelaia and Hogarth (2010) investigated the effects of a random perturbation of relative performance rankings. They found that low-skilled participants took greater risk by entering the market more in the presence as opposed to absence of this factor. That is, the participants with less skill were more risk seeking when randomness played a greater role. Our empirical findings replicate this experimental result on increased risk taking by unskilled individuals when relative performance of contestants is more affected by random factors.

Finally, our work also contributes to studies in finance on the behavior of high-skilled and low-skilled analysts (Clarke \& Subramanian, 2006; Easterwood \& Nutt, 1999; Friesen \& Weller, 2006; Hilary \& Menzly, 2006). Although much research already considers the interplay of analysts' skill and herding behavior (e.g., Clement \& Tse, 2005; Hong et al., 2000), we are among the first to examine the moderating effect of market conditions. By considering skill, we also augment the results of Song et al. (2009) who documented the effect of market conditions (specifically, the uncertainty about companies' earnings) on analysts' deviation from consensus. Importantly, our work is distinct from the existing literature on financial analysts' behavioral biases. For example, Hilary and Menzly (2006) studied the short-term dynamics of analysts' forecasts and showed that analysts become overconfident after a series of accurate forecasts, leading to greater deviation-from-consensus and lower accuracy in the shortterm. Our work differs by considering past forecast accuracy over a long period, as opposed to the recent past. The long-term track record is more likely to reflect analysts' skill independent of short-term behavioral biases such as overreaction.

\section{Limitations and future directions}

Our work is subject to limitations that suggest opportunities for future research. First, whereas deviating from consensus forecasts implies reputational and career risks for financial analysts, the upside of outperforming peers by providing more extreme forecasts-if they turn out to be correct ex post-is also substantial. However, one might still question whether deviating from consensus implies explicit risk taking because, psychologically, analysts may not necessarily experience this as risky. Future research should address this issue by assessing analysts' perceptions of the riskiness of different strategies.

Second, we based our hypothesis on the idea that, compared with their high-skilled counterparts, low-skilled analysts have much to lose by issuing extreme forecasts when market conditions are calm but less when conditions are volatile. In the latter, their behavior is similar to buying lottery tickets with highly skewed payoffs. That is, although success is unlikely for almost all low-skilled analysts, such behavior may increase their chances of "winning" the professional contest (Cabral, 2003; Tsetlin et al., 2004). Nonetheless, other reputation-related issues should also be investigated in future research. Prendergast and Stole (1996) suggest that people who desire to establish reputations for being quick learners - that is, those who learn and respond to new information - may end up exaggerating their information and making long shots. For example, an executive who does not change the course of action established by her predecessor may be viewed as lacking initiative. Thus, 
her incentives are to "overact". Similarly, in volatile markets, where information is arriving at a fast pace, there are strong incentives for low-skilled financial analysts to exaggerateby making outlandish forecasts - to establish a reputation for effective learning.

On a related note, literature on self-serving attributions can provide an alternative explanation for our results. In particular, self-serving attribution bias implies that people take individual credit for success but blame failure on external causes (Heider, 1976). In Western cultures, this and other illusions help satisfy the need to maintain positive self-views (Heine, Lehman, Markus, \& Kitayama, 1999). It can be argued that when market volatility is high and luck is important in affecting outcomes, the risk of damaging self-image by failing after making outlandish calls is reduced-because uncontrollable events can be used to explain poor performance. In other words, market uncertainty provides external reasons to dissipate self-doubts as well as manage professional reputation in case of failure. Because low-skilled analysts lack demonstrated expertise that might protect them from negative attributions (Dodgson \& Wood, 1998; Heath \& Tversky, 1991), these additional possible explanations should be more important than for high-skilled analysts. Thus, in striving to demonstrate high performance relative to peers, low-skilled analysts will take even more risk in the periods of high volatility than their high-skilled counterparts.

Importantly, our hypothesis assumes that to reach their reputational goals, analysts take rational, calculated reputational risks-by choosing whether to make outlandish forecasts. On the other hand, an alternative explanation is that forecasting is more difficult for all analysts when market uncertainty is high - that is, they all "know" less in such conditions. Consistent with the matching hypothesis (Brehmer, 1976), greater variability in judgment reflects more variability in the environment. The finding that the difference in deviation-from-consensus between low-skilled and highskilled analysts is amplified when markets become more volatile could simply mean that low-skilled analysts do their best in volatile markets but do not know any better. Although our empirical results support our hypothesis, our data did not allow for explicit tests of the mechanisms. Further researchboth experimental and empirical-is needed to explicate the processes underlying our findings.

Finally, our conclusions are based on the behavior of financial analysts. In common with many other professions, the tasks of financial analysts are competitive and outcomes depend on both skill and luck. A natural question, therefore, is to specify boundary conditions. Do the same types of skill $x$ luck interactions occur in other competitive environments in the financial world (e.g., portfolio and fund managers) or elsewhere (e.g., launching new products or services, competitions in sports or for jobs, etc.)? Our paradigm provides a useful framework for considering these issues.

\section{CONCLUSION}

Our empirical results suggest that, when market volatility increases, low-skilled analysts exhibit greater risk taking by making forecasts that deviate more from consensus. Although the explicit processes underlying our findings should be addressed in future research, our results are robust to several control variables, alternative econometric estimations, and measures of skill and market uncertainty. Moreover, our findings also provide novel proxies for analysts' skill in forecasting. Specifically, observing how much bolder an analyst becomes during times of high uncertainty can signal the analyst's skill level and predict future accuracy beyond traditional measures of skill based on analysts' past performance.

\section{ACKNOWLEDGEMENTS}

The authors appreciate the insightful comments on earlier versions of this paper by Gilles Hilary, Joro Kolev, two anonymous reviewers, and the editor. Hogarth's work was supported by the Spanish Ministerio de Ciencia e Innovación Grant ECO2009-09834.

\section{REFERENCES}

Aiken, L. S., \& West, S. G. (1991). Multiple regression: Testing and interpreting interactions. Newbury Park, CA: Sage.

Armstrong, J. S. (2001). Principles of forecasting: A handbook for researchers and practitioners. Boston, MA: Kluwer Academic.

Atkinson, J. W. (1957). Motivational determinants of risk-taking behavior. Psychological Review, 64, 359-372.

Avci, B., Loufti, Z., Mihm, J., \& Keck, S. (2011). Comparison as incentive: Newsvendor decisions in a social context. INSEAD Working Paper.

Avery, C. N., \& Chevalier, J. A. (1999). Herding over the career. Economics Letters, 63, 327-333.

Brehmer, B. (1976). Note on clinical judgment and the formal characteristics of clinical tasks. Psychological Bulletin, 83(5), 778-782.

Cabral, L. (2003). R\&D competition when firms choose variance. Journal of Economics and Management Strategy, 12, 139-150.

Camerer, C., \& Lovallo, D. (1999). Overconfidence and excess entry: An experimental approach. American Economic Review, 89(1), 306-318.

Chevalier, J. A., Ellison, G. (1997). Risk-taking by mutual funds as a response to incentives. Journal of Political Economy, 105(5), 1167-1200.

Chevalier, J. A., \& Ellison, G. (1999). Career concerns of mutual fund managers. Quarterly Journal of Economics, 114(2), 389-432.

Clarke, J., \& Subramanian, A. (2006). Dynamic forecasting behavior by analysts: Theory and evidence. Journal of Financial Economics, 80, 81-113.

Clemen, R. T. (1989). Combining forecasts: A review and annotated bibliography. International Journal of Forecasting, 5, 559-609.

Clement, M. (1999). Analyst forecast accuracy: Do ability, resources, and portfolio complexity matter? Journal of Accounting and Economics, 27, 285-303.

Clement, M., \& Tse, S. Y. (2003). Do investors respond to analysts' forecast revisions as if forecast accuracy is all that matters? The Accounting Review, 78, 227-249.

Clement, M., \& Tse, S. (2005). Financial analyst characteristics and herding behavior in forecasting. Journal of Finance, 60(1), 307-341.

Cohen, J., \& Dearnaley, E. J. (1962). Skill and judgment of footballers in attempting to score goals: A study of psychological probability. British Journal of Psychology, 53, 71-86. 
Cohen, L., Malloy, C., \& Frazzini, A. (2010). Sell-side school ties. Journal of Finance, 65, 1409-1437.

Cooper, R. A., Day, T. E., \& Lewis, C. M. (2001). Following the leader: A study of individual analysts' earnings forecasts. Journal of Financial Economics, 61, 383-416.

Denrell, J., \& Fang, C. (2010). Predicting the next big thing: Success as a signal of poor judgment. Management Science, 56(10), 1653-1667.

Dodgson, P. G., \& Wood, J. V. (1998). Self-esteem and the cognitive accessibility of strengths and weaknesses after failure. Journal of Personality and Social Psychology, 75(1), 178-197.

Easterwood, J., \& Nutt, S. R. (1999). Inefficiency in analysts' earnings forecasts: Systematic misreaction or systematic optimism? Journal of Finance, 54(5), 1777-1797.

Fama, E. F., \& MacBeth, J. D. (1973). Risk, return and equilibrium: Empirical tests. Journal of Political Economy, 81, 607-636.

Fang, L., \& Yasuda, A. (2009). The effectiveness of reputation as a disciplinary mechanism in sell-side research. Review of Financial Studies, 22, 3735-3777.

Friesen, G., \& Weller, P. (2006). Quantifying cognitive biases in analyst earnings forecasts. Journal of Financial Markets, 9(4), 333-365.

Gaba, A., Tsetlin, I., \& Winkler, R. L. (2004). Modifying variability and correlations in winner-take-all contests. Operations Research, 52(3), 384-395.

Gleason, C., \& Lee, C. (2003). Analyst forecast revisions and market price discovery. The Accounting Review, 78, 193-225.

Heath, C., \& Tversky, A. (1991). Preference and belief: Ambiguity and competence in choice under uncertainty, Journal of Risk and Uncertainty, 4, 5-28.

Heider, F. (1976). A conversation with Fritz Heider. In J. H. Harvey, W. J. Ickes, \& R. F. Kidd (Eds.), New directions in attribution research (Vol. 1, 47-61). Hillsdale, NJ: Erlbaum.

Heine, S. J., Lehman, D. R., Markus, H. R., \& Kitayama, S. (1999). Is there a universal need for positive self-regard? Psychological Review, 106, 766-794.

Hilary, G., \& Menzly, L. (2006). Does past success lead analysts to become overconfident? Management Science, 52(4), 489-500.

Hogarth, R. M., \& Karelaia, N. (2007). Heuristic and linear models of judgment: Matching rules and environments. Psychological Review, 114(3), 733-758.

Hong, H., Kubik, J., \& Solomon, A. (2000). Security analysts' career concerns and herding of earnings forecasts. The RAND Journal of Economics, 31(1), 121-144.

Karelaia, N. (2006). Thirst for confirmation in multi-attribute choice: Does search for consistency impair decision performance? Organizational Behavior and Human Decision Processes, 100, 128-143.

Karelaia, N., \& Hogarth, R. M. (2008). Determinants of linear judgment: a meta-analysis of lens model studies. Psychological Bulletin, 134(3), 404-426.

Karelaia, N., \& Hogarth, R. M. (2010). The attraction of uncertainty: Interactions between skill and levels of uncertainty in market-entry games. Journal of Risk and Uncertainty, 41(2), 141-166.

Keynes, J. M. (1965). The general theory of employment, interest, and money. New York: Harcourt, Brace \& World, First Harbinger Edition.

Langer, E. J. (1975). The illusion of control. Journal of Personality and Social Psychology, 32(2), 311-328.

Larrick, R. P., Mannes, A. E., \& Soll, J. B. (2011). The social psychology of the wisdom of crowds. In J. I. Krueger (Ed.), Frontiers of social psychology: Social psychology and decision making. Philadelphia: Psychology Press.
Lee, J.-W., \& Yates, J. F. (1992). How quantity judgment changes as the number of cues increases: An analytical framework and review. Psychological Bulletin, 112(2), 363-377.

March, J. (1991). Exploration and exploitation in organizational learning. Organization Science, 2(1), 71-87.

Mikhail, M. B., Walther, B. R., \& Willis, R. H. (1997). Do security analysts improve their performance with experience? Journal of Accounting Research, 35, 131-157.

Moore, D. A., \& Healy, P. J. (2008). The trouble with overconfidence. Psychological Review, 115(2), 502-517.

Prendergast, C., \& Stole, L. (1996). Impetuous youngsters and jaded old-timers: Acquiring a reputation for learning. Journal of Political Economy, 104(6), 1105-1134.

Scharfstein, D. S., Stein, J. C. (1990). Herd behavior and investment. American Economic Review, 80(3), 465-489.

Song, M., Kim, D., \& Won, C. (2009). Earnings uncertainty and analyst forecast herding. Asia-Pacific Journal of Financial Studies, 38(4), 545-474.

Surowiecki, J. (2004). The wisdom of crowds. London: Little, Brown.

Trueman, B. (1994). Analyst forecasts and herding behavior. Review of Financial Studies, 7(1), 97-124.

Tsetlin, I., Gaba, A., \& Winkler, R. (2004). Strategic choice of variability in multi-round contests and contests with handicaps. Journal of Risk and Uncertainty, 29(2), 143-158.

\section{Authors' biographies:}

Theos Evgeniou is an Associate Professor of Decision Sciences and Technology Management at INSEAD. He received his BS and $\mathrm{PhD}$ from MIT. He works on data analytics and preference measurement methodologies, focusing on marketing and finance questions, and he has consulted for a number of companies in these areas.

Lily Fang is an Assistant Professor of Finance at INSEAD, Singapore. She received her $\mathrm{PhD}$ in finance from the Wharton School, University of Pennsylvania. Her research interests include capital markets, the relation between the media and financial markets, and financial intermediaries such as stock analysts, banks, and fund managers.

Robin M. Hogarth is an ICREA Research Professor at Universitat Pompeu Fabra, Barcelona. He previously held appointments at INSEAD, London Business School and the University of Chicago. He is a past president of both the Society for Judgment and Decision Making and the European Association for Decision Making.

Natalia Karelaia is an Assistant Professor of Decision Sciences at INSEAD, France. She received her $\mathrm{PhD}$ in management from Universitat Pompeu Fabra, Barcelona, Spain. Her research interests include decision making, human behavior in competitive environments, self-identity, and prosocial behavior.

\section{Authors' addresses:}

Theodoros Evgeniou and Natalia Karelaia, INSEAD, Fontainebleau, France.

Lily Fang, INSEAD Singapore.

Robin M. Hogarth, ICREA and Universitat Pompeu Fabra, Barcelona, Spain. 